\title{
APICAL MICROLEAKAGE OF FOUR MATERIALS AFTER ROOT END RESECTION (IN VITRO STUDY)
}

\author{
E. Radeva ${ }^{1}$, T. Usunov ${ }^{1}$, I. Ivanov ${ }^{2}$ and G. Genchev ${ }^{3}$ \\ ${ }^{1}$ Department of Conservative Dentistry, Faculty of Dental Medicine, MU - Sofia, Bulgaria \\ ${ }^{2}$ Dentist \\ ${ }^{3}$ Department of Health Economics, Faculty of Public Health, MU - Sofia, Bulgaria
}

Summary. Hermetic sealing of the apical area after root end resection is essential to the success of endodontic surgery. To compare microleakage after root end resection of the two bioceramic sealers without retrograde filling - Total Fill BC Sealer and MTA Fillapex, and two materials for retrograde filling-MTA and Biodentine, using the method of penetration of dye $-2 \%$ methylene blue. Forty eight extracted single-rooted human teeth were used in this study. The resection was made at $3 \mathrm{~mm}$ from the root tip at an angle of 90 degree to the long axis of the tooth. The teeth were divided into 4 groups: 1st group $(n=9)-$ root canal obturation with Total Fill BC Sealer without retrograde filling; 2nd group $(n=8)$ - root canal obturation with MTA Fillapex without retrograde filling. 3rd group $(n=10)-$ retrograde ultrasonic cavity preparation and filling with MTA. 4th group $(n=8)-$ retrograde ultrasonic cavity preparation and filling with Biodentine. The outer surface of the root was covered with two layers of varnish, with the exception of the apical $3 \mathrm{~mm}$ and then immersed in $2 \%$ methylene blue for $72 \mathrm{~h}$. The degree of penetration of the dye is measured in millimeters. The data was entered and processed with the statistical package IBM SPSS Statistics 22.0. We reject the null hypothesis when $p<0.05$. With significantly higher value is the arithmetic mean of the group with the root canal obturation with Total Fill BC Sealer without retrograde filling 2,01 mm; versus a retrograde filling with MTA $-0,68 \mathrm{~mm}$ and Biodentin $-0,51 \mathrm{~mm}$; and no statistically significant difference with the group root canal obturation with MTA Fillapex $-1,76 \mathrm{~mm}$. In the four material microleakage dye was observed, but to varying degrees.

Key words: apical microleakage, Total Fill BC Sealer, MTA Fillapex, Biodentine, MTA 


\section{INTRODUCTION}

he wide variety of materials used in retrograde filling determines the need for detailed analysis. In the scientific literature discussed are: amalgam, glass ionomer cements (Vitremer), zinc oxide eugenol cements (SuperEBA, IRM, Rickert), mineral trioxide aggregate - MTA, phosphate cements, calcium hydroxide cements (Sealapex, Sealer 26) filling agents based on epoxy resins (AH 26, AH Plus) and bio-ceramic sealer [1, 5, 17, 21, 27]. The selection of suitable material suggests successfuly conducted treatment. As an ideal were identified those that are non-toxic, non-carcinogenic, biocompatible preventing percolation of tissue fluids. The sealing capacity of the materials should remain constant, regardless of body fluids and moisture in the environment $[10,20]$. It should be easily applied and radiopaque [26]. MTA (mineral trioxide aggregate) has proven sealing qualities in cases as communications between root-canal system and outer root surface [19, 24]. Biodentin is indicated for use in deep carious lesions, pulp cover perforations in the furcation and root, internal and external resorption, retrograde filling in apical surgery. Compared to the MTA it has a faster setting time, which reduces the risk of bacterial contamination [13]. There is very little data regarding the sealing ability of MTA Fillapex. It is therefore appropriate that it can be evaluated by comparing with other sealers, which are widely referred in the literature. MTA Fillapex (Angelus, Brazil) is relatively new cement-based MTA. The material has improved handling properties as compared to MTA $[3,6]$. Sealed lateral canals does not lead to recolor tooth prevents recontamination of endodontic system releases calcium ions, which provide rapid tissue regeneration [18].

Totalfill BC Sealer is recently presented bio-ceramic sealer consisting of: zirconium oxide, calcium silicate, calcium phosphate, monobasic calcium hydroxide and the like $[11,14]$. To solidify assumes the required moisture of the dentinal tubules in the wall of the root canal. Channel itself should be well dry with paper points before putting sealer on it.

The aim of the study is to compare apical microleakage after resection of the root tip of two bio-ceramic sealers without retrograde sealing - Total Fill BC Sealer and MTA Fillapex and two material retrograde obturation (MTA, Dentsply and Biodentine, Septodont) using the method of penetration dye $-2 \%$.

\section{MATERIAL AND METHODS}

Forty eight extracted single-rooted human teeth were used in this study. The resection was made at $3 \mathrm{~mm}$ from the root tip at an angle of 90 degree to the long axis of the tooth. The teeth were divided into 4 groups:

Group $1(n=10$ teeth): a retrograde cavity with ultrasound and retrograde obturation with MTA were done. 
Group 2 ( $n=8$ teeth): a retrograde cavity with ultrasound and retrograde obturation with Biodentin were prepared.

Group 3 ( $n=9$ teeth): root canal filling with Total Fill BC Sealer without retrograde filling.

4 group ( $n=8$ teeth): root canal filling with MTA Fillapex without retrograde filling.

After the apical cavity and retro filling were done the teeth were placed in a saline for three weeks. Then dried well and the outer surface of the root was covered with two layers of varnish, except the apical $3 \mathrm{~mm}$. After drying of the varnish, all the teeth were immersed in $2 \%$ methylene blue for $72 \mathrm{~h}$ to study of the degree marginal leakage in both types of material for retrograde filling. After removal from the dye teeth were placed under running water for $24 \mathrm{hr}$, then left to dry in order to fixation of the dye. The teeth were cut along the longitudinal axis in buccal-lingual direction with microtome Leica SP1600 for visualization degree of penetration of the dye between the sealing material and the channel wall.

Data was processed with statistical package IBM SPSS Statistics 22.0. Accepted was the null hypothesis rejected at $p<0.05$. The following methods were used:

1. Variation Analysis - performance evaluation of central tendency and dispersion of the data. 2. Graphical Analysis - visualization of results.

3. The non-parametric test of Shapiro-Wilk - verification data distribution normality.

4. Nonparametric test Kruscal-Wallis - for hypothesis testing for differences between several unrelated samples.

5. Nonparametric test of Mann-Whitney - for hypothesis testing for difference between two unrelated samples.

\section{RESULTS}

The results showed a statistically significant difference in the micro-permeability of the dye $-2 \%$ methylene blue in the apical region after the resection of the root tip in the various groups of study (Table 1 and Fig. 1, Fig. 2-5).

The highest value of dye penetration was the group with the root canal filling with Total Fill BC Sealer without retrograde filling $-2.01 \mathrm{~mm}$ did not establish a statistically significant difference compared to group root canal filling with MTA Fillapex without retrograde filling $-1.76 \mathrm{~mm}$. The remaining two groups did not differ statistically on the research indicator, namely in group of retrograde cavity with ultrasound and retrograde filling with MTA $-0.68 \mathrm{~mm}$ and of retrograde cavity with ultrasound and retrograde filling with Biodentin $-0.51 \mathrm{~mm}$. 
Table 1. Comparative analysis of microleakage of dye methylene blue in the apical region after resection of the root tip in the studied different groups

\begin{tabular}{|c|c|c|c|c|c|c|}
\hline \multirow{2}{*}{ Group } & \multirow{2}{*}{$n$} & \multirow{2}{*}{$\bar{X}$} & \multirow{2}{*}{ SD } & \multicolumn{3}{|l|}{$P$} \\
\hline & & & & 2 & 3 & 4 \\
\hline $\begin{array}{l}\text { Preparation of retrograde cavity with } \\
\text { ultrasound and retrograde filling with MTA }\end{array}$ & 10 & $0,68 \mathrm{a}$ & 0,98 & 0,897 & 0,017 & 0,696 \\
\hline $\begin{array}{l}\text { Preparation of retrograde cavity with } \\
\text { ultrasound and retrograde filling with } \\
\text { Biodentin }\end{array}$ & 8 & $0,51 a$ & 0,48 & & $<0,001$ & 0,645 \\
\hline $\begin{array}{l}\text { Obturation of root canal with Total Fill BC } \\
\text { Sealer without retrograde filling }\end{array}$ & 9 & $2,01 b c$ & 0,28 & & & 0,093 \\
\hline $\begin{array}{l}\text { Obturation of root canal with MTA Fillapex } \\
\text { without retrograde filling }\end{array}$ & 8 & $1,76 \mathrm{ac}$ & 2,80 & & & \\
\hline
\end{tabular}

* - Identical letters stand for lack of a significant difference; different for the existence of such $(p<0.05)$

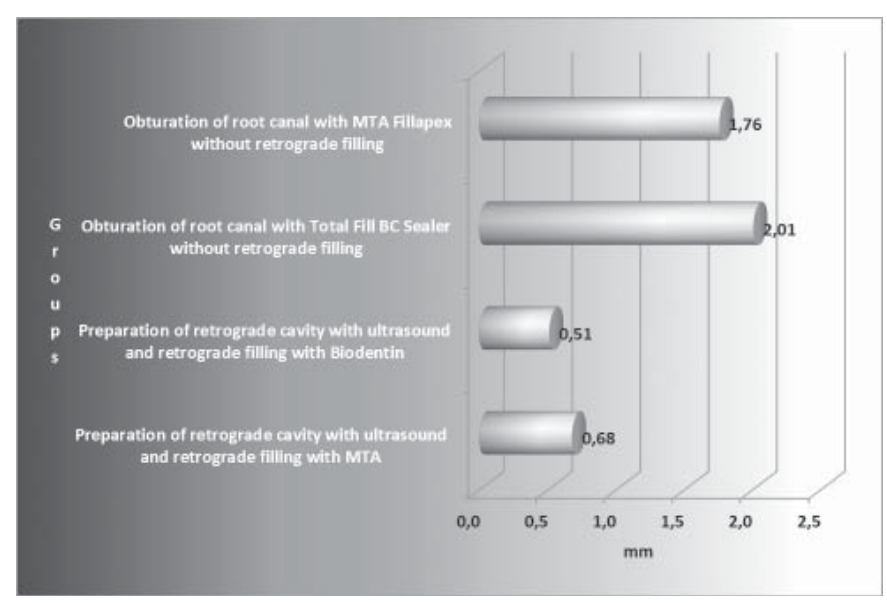

Fig. 1. Comparative analysis of microleakage of dye methylene blue in the apical region after resection of the root tip in different groups of study

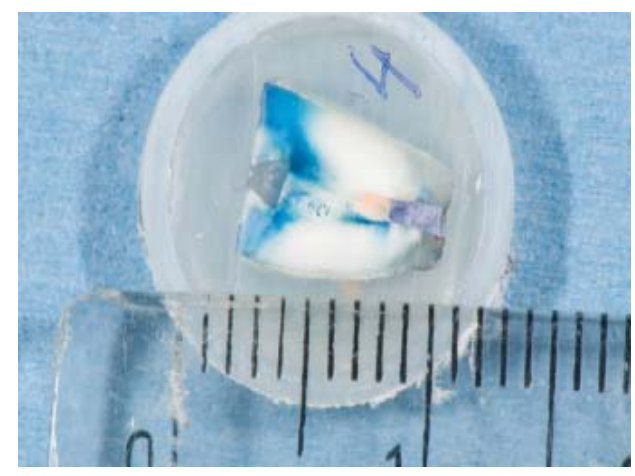

Fig. 2. Preparation of retrograde cavity with ultrasound and retrograde obturation with MTA

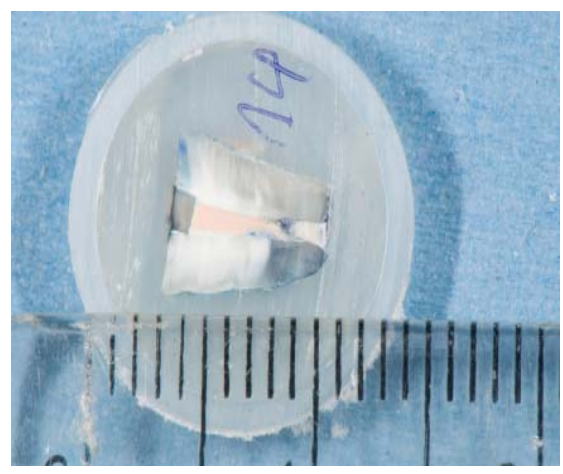

Fig. 3. Preparation of a retrograde cavity with ultrasound and retrograde filling with Biodentin 


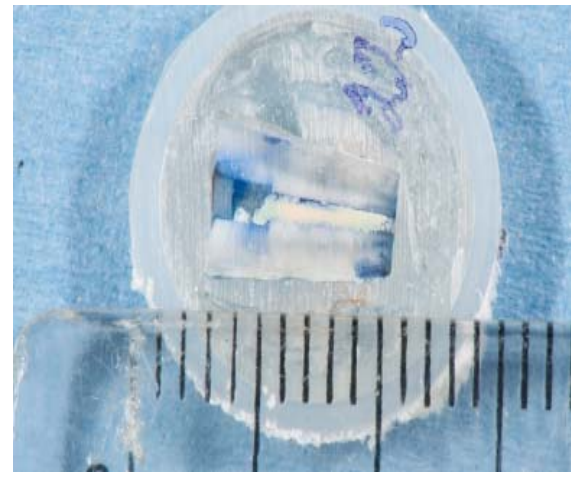

Fig. 4. Filling with Total Fill BC Sealer without retrograde filling

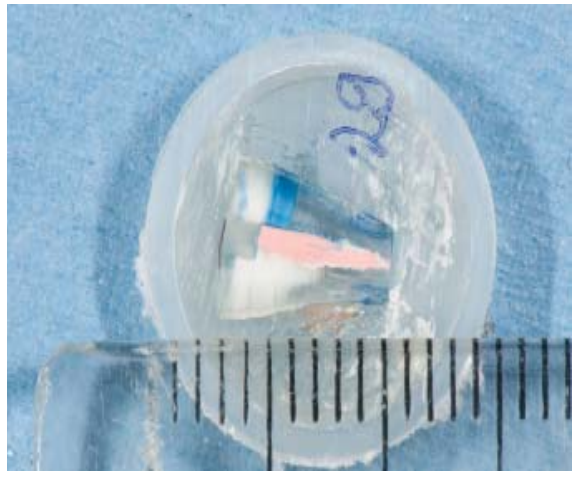

Fig. 5. Filling with MTA Fillapex without retrograde filling materia

\section{DISCUSSION}

The aim of endodontic treatment is the elimination of microorganisms and their products from root canal in periapical tissues and vice versa - from periapical area in the root canal. Conventional root canal treatment is the preferred method of choice for achieving endodontic success. In case of failure the approach to reach the apical lesion is a retrograde one. Retrograde filling aims to achieve apical sealing to prevent the passage of microorganisms and their products in periapical tissues. The mentioned apical sealing according to some authors is the most important condition for successfully conducted treatment $[8,16]$.

The most widely studied method for the assessment of sealing quality was dye penetration. These tests are cheap, easy to implement and safer than radioisotopes $[7,15,26]$. The dyes which are used are Indian ink solution of erythrosine $B$, aqueous magenta, fluorescent solution, methylene blue and others. The authors Kersten and Moorer reported that the infiltration of the molecules of the methylene blue molecules is comparable to that of small bacterial metabolic products having similar molecular size. During the stay of the tested materials in the methylene blue no significant infiltration was found $[9,12]$. Some meaming proved the depth of the prepared access cavity and the angle of the cut to the axial axis of the tooth root. The increase of the angle leads to greater leakage due to exposure over the dentinal tubules $[7,9]$. For this reason, it is recommended that the apical resection must be made perpendicular to the axial axis of the tooth.

One of the most commonly studied materials for retrograde sealing is dental amalgam. Examined were a number of generations of dental amalgams: no zinc enriched with copper and more. Researchers verify the seal cavities in which are dried and those that are contaminated with blood, to be able to come closer to the in vivo 
conditions. Johnson et al. demonstrated that contaminated blood amalgam reduced microleakage. Bates and colleagues tracked microleakage in dental amalgam, EVA and MTA. They reached the conclusion that it is minimed in MTA [2].

Mineral trioxide aggregate is a powder which is made of fine hydrophilic particles of tricalcium silicate, dicalcium silicate, tricalcium aluminum, calcium sulfate, and bismuth oxide. MTA is known for its biocompatibility, effectively sealing properties, low solubility and radiopacity that is slightly larger than that of the dentine. MTA is initially used to treat a root perforations and later in the apical sealing due to its ability to harden in humid conditions.

Studies of Torabinejad [25] exhibited small penetration of Staphylococcus epidermidis in the channel when it is retrograde sealed with MTA. The same author compared the time of solidification, which in MTA is longer than that of a dental amalgam, but marginal adaptation of MTA is significantly better than that of the dental amalgam and IRM [23].

There are several studies in modern literature on micro leakage of MTA Fillapex. Antonio Braitt et al (4) found marginal leakage of MTA Fillapex of $0.34 \mathrm{~mm}$. Relatively more is discovered by the team of Sönmez - between 3.1 and $10 \mathrm{~mm}$ [22]. In root canal obturation with MTA Fillapex without retrograde filling our results have shown a degree of microleakage $-1.76 \mathrm{~mm}$.

\section{CONCLUSION}

Complete elimination of marginal leakage in the channel system is difficult to achieve. This also applies to the lateral and additional channels, and for other anatomical variations playing a role in the periapical pathology.

This study was supported by Medical University - Sofia, contract № 45/2015

\section{REFERENCES}

1. Arx T, M. Pennarocha, S. Jensen. Prognostic factors in apical surgery with root-end filling: A metaanalysis. JOE, 36, 2010, 6, 957-963.

2. Bates C, Carnes D. longitudinal sealing ability of MTA as a root-end filling material. J Endod: 22, 1996, 575-578.

3. Bodrumlu E, Tunga U. The apical sealing ability of a new root canal filling material. Am J Dent. 20, 2007:295-8.

4. Braitt AH, Andrade CA, Limoeiro AGS, Muniz YS, Bueno CES. Evaluation of apical marginal leakage in teeth retrofilled with MTA/water and MTA/Fillapex: a study in avulsed teeth. Dental Press Endod. 5, 2015 Jan Apr, 1:30-9.

5. Dammaschke T. Root-end filling with a new Bioactive cement. AEGIS, 8, 2012, 3.

6. Dultra F, Barroso JM, Carrasco LD, Capelli A, Guerisoli DMZ, Pecora JD. Evaluation of apical microleakage of teeth sealed with four differents root canal sealers. J Appl Oral Sci. 14, 2006:341-5. 
7. Gutmann J, Harrison J. Surgical endodontics. Boston: Blackwell Scientific Publications, 1991,23063.

8. Harfty F et al: Success rate of apicoectomy. A retrospective study of 1.016 cases. Br Dent H 129, 1970: 407-13.

9. Higa R, Torabinejad $\mathrm{M}$ et al. The effect of storage time on the degree of the degree of dye leakage of root end filling materials. Int Endod J 27, 1994, 252-256.

10. Johnson J, Anderson R, Pashley D. Evaluation of the seal of various amalgam products used as root-end fillings. J Endod 10, 1995, 505-508.

11. Ken K. A review of bioceramic technology in endodontics. Roots 2012, 4, 6-12.

12. Kersten H, Moorer W. Principles and molecules in endodontic leakage. Int Endod J 22, 1989, 118-124.

13. Kokate Sh, Pawar A. An in vitro comparative stereomicroscopic evaluation of marginal seal between MTA, glass inomer cement \& biodentine as root end filling materials using $1 \%$ methylene blue as tracer. 2013.

14. Kossev D, Stefanov V. Ceramics-based sealers as new alternative to currently used endodontic sealers. Roots 2009;1:42.

15. MacNell K, Beatty R. Ketac silver and Fiji II as reverse fillings: a dye study. J Dent Res 66, 1987, 297.

16. Mattison $\mathrm{G}$ et al: Microleakage of retrograde amalgams. J of Endod 8, 1982, 355-8.

17. McDonald NJ, TC Dumsha. An evaluation of the retrograde apical seal using dentine bonding materials. Int Endod J, 23, 1993, 156-162.

18. Nagas E, Uyanik MO, Eymirli A, Cehreli ZC, Vallittu PK, Lassila LV, et al. Dentin moisture conditions affect the adhesion of root canal sealers. J Endod 38, 2012, 240-4.

19. Nakata TT, Bae KS, Baumgartner JC. Perforation repair comparing mineral trioxide aggregate and amalgam using an anaerobic bacterial leakage model. J Endod 24, 1998, 184-186.

20. Philip S, Bamiduro R. Effect of apical resection and reverse fillings on thermafil root canal obturations. J of Endod 16, 1990, 227-229.

21. Shahi S. et al. Comparison of the sealing ability of mineral trioxide aggregate and Portland cement used as root-end filling materials. Journal of Oral Science 53, 2011, 4, 517-522.

22. Sönmez I, Oba A, Sönmez D, Almaz M. In vitro evaluation of apical microleakage of a new MTAbased sealer. European Archives of Paediatric Dentistry: 13, 6, 2012, 252-255.

23. Torabinejad $\mathrm{M}$, Watson $\mathrm{T}$, Ford $\mathrm{T}$. Sealing ability of mineral trioxide aggregate when used as a root end filling material. J Endod 19, 1993, 591-595.

24. Torabinejad M, Hong CU, Lee SJ, Monsef M, Pitt Ford TR. Investigation of mineral trioxide aggregate for root end filling in dogs. J Endod 21, 1995, 603-608.

25. Torabinejad trioxide aggregate as a $M$, Rastegar $A$, Kettering J. Bacterial leakage of mineral rootend filling material. J Endod: 21, 1995, 109-112.

26. Torabinejad M, Pitt T. Root end filling materials: a review. Endod Dent Traumatol 12, 1996, 161-178.

27. Xavier C. et al. Root-end filling materials: apical microleakage and marginal adaptation. J of Endod, $31,2005,7,539-542$.

$\equiv \quad$ Corresponding author:

Assoc. Prof. Elka Radeva, DMD, PhD

Department of Conservative dentistry

Faculty of Dental Medicine

Medical University

1, G. Sofiyski blvd.

Bg - 1431 Sofia

e-mail: eliradeva@abv.bg 